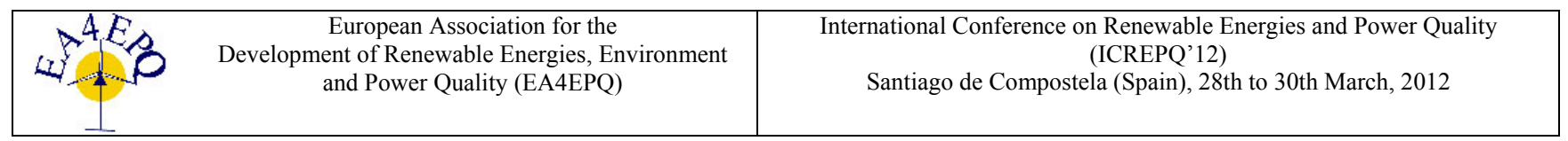

\title{
Optimal orientation procedure of photovoltaic solar systems through the use of a multicellular photovoltaic sensor
}

\author{
J.C. Sáenz-Díez Muro ${ }^{1}$, E. Jiménez Macías ${ }^{1}$, J.M. Blanco Barrero ${ }^{1}$, J. Blanco Fernández ${ }^{2}$, \\ Eduardo Martínez Cámara, M. Pérez de la Parte \\ ${ }^{1}$ Department of Electrical Engineering \\ 2 Department of Mechanical Engineering \\ E.T.S.I.I., University of La Rioja. c/Luis de Ulloa, 20. 26004. Logroño (Spain) \\ Phone/Fax number: +0034 941 299477/478, e-mail: \\ juan-carlos.saenz-diez@unirioja.es ; juan-manuel.blanco@unirioja.es; emilio.jimenez@unirioja.es
}

\begin{abstract}
This paper presents a method of orientation of solar photovoltaic systems through the use of a multicellular photovoltaic sensor. The sensor consists of a set of calibrated photovoltaic solar cells. The cells are arranged in different planes $\left(0^{\circ}, 15^{\circ}, 30^{\circ}, 45^{\circ}, 60^{\circ}, 75,90^{\circ}\right)$ on a support, concave or convex. The solar cells detect the radiation in each of the planes, allowing, on the one hand, to control in real time the optimal orientation of orientable solar photovoltaic systems, both in one or two axes, and on the other hand, to perform a data acquisition of the actual solar radiation over a period of time in each of the orientations, in order to determine effectively simply and empirically what is the ideal orientation for the systems to be installed.
\end{abstract}

\section{Key words}

Solar photovoltaic system, photovoltaic solar cell calibrated, Renewable Electric Energy, Sustainable Buildings.

\section{Introduction}

Today it is easy to know the relative position of the sun at any moment on a place, and therefore can be known analytically how to target any device in an optimal way respect to direct solar radiation. But solar radiation not only has direct component (which comes only from solar disk), but also important is the diffuse radiation (which comes from the sky and is visible on the surface scavenger), and reflected or albedo radiation (the coming from the environment).

This paper presents a method of orientation of solar photovoltaic systems through the use of a multicellular photovoltaic sensor that allows real-time control for optimal orientation of solar photovoltaic systems, both in one or two axes, and to perform a real data acquisition of solar radiation over a period of time, to determine effectively simply and empirically what is the ideal orientation for the systems to be installed.

\section{Solar radiation}

The Sun is the brightest element of the universe observed from Earth and is the largest source of electromagnetic energy of our planet. Earth captures only an infinitesimal part of all the energy the sun radiates. Almost all energy resources available on earth, including fossils, are related to the Sun, with the exception of the energy contained in the terrestrial magma (geothermal), the stored radioactive materials (nuclear energy sources) and other minerals, and associated with surges (tidal) from planetary gravitational potential, the remaining resources are related in some way with solar radiation.

All the energy locked in coal, oil and gas is the result of organic matter in the past that used photosynthesis; and hydro and wind power are a result of climatic variations, of which the sun is the engine. In the case of biomass, plants through photosynthesis and the nutritional benefits of the land transform solar radiation into plant material. Man has used the sun as a heat source since immemorial times; technological advances initiated in the past half century can transform solar radiation directly into electricity. All the things radiate energy according to their temperature, which is emitted as electromagnetic waves.

The frequency distribution of the value depends on the temperature: the higher, the lower the center wavelength of the emission spectrum. The equivalent temperature of the visible layer of the Sun, the photosphere, is that of a black body at $6,000^{\circ} \mathrm{C}$ so that, according to Planck's law, most of the energy is focused on the visible spectrum (wavelengths between 350 and $750 \mathrm{~nm}$ ), although there is a very important part in the ultraviolet and near infrared. 
Our planet, understood as a whole, as the sum of inanimate matter, biological material, a permanent source of energy (the sun), and evolution, has reached a difficult balance involved in the composition and nature of the atmosphere and the energy falling at every moment on the surface.

The atmosphere consists essentially of nitrogen and oxygen, in a 4 to 1 ratio, other trace gases, such as the socalled greenhouse gases, water vapor, aerosols and particulates in suspension, which behaves as a heat trap. The solar radiation passes through the atmosphere, as it is transparent to the wavelengths of the solar spectrum, the land surface is heated as a result of this energy and, in turn, emits electromagnetic radiation depending on the temperature reached, much lower than the equivalent of the sun, so that emits at wavelengths much higher than those of the incident radiation, in the infrared area, which presents lower energy than the visible spectrum.

However, the atmosphere is practically opaque to these electromagnetic frequencies, and absorbs most of the radiation emitted by the Earth. This process is extremely complex and constantly evolving; is what determines the range of variation of ambient temperature on our planet. Sample of the continuing evolution of this process is the average temperature increase on the earth, which is called greenhouse effect, as a result of anthropogenic emissions of certain gases (mainly carbon dioxide, sulfur oxides and nitrogen, and methane ) caused largely by burning fossil fuels and deforestation.

Recall for a moment the images of spacecraft in orbit around the Earth, so familiar from forty years ago. In them, the space is completely black and the objects are seen because of the sunlight they reflect. However, once it passes through the atmosphere towards the Earth, space is colored in shades of blue, white, red, all indicative that there is power emission. What happens is that the atmosphere, containing gases and particles, reflects, absorbs and diffracts light from the Sun; the whole sky is a transmitter. While the solar radiation reaching the first layers of the atmosphere (called extra-atmospheric), can be characterized analytically with certain simplicity; the position of the emitting source is clearly identified, can be considered timely (just takes $0.5^{\circ}$ ) and unique, because the energy coming from other objects is negligible; climate variability makes the transparency of the atmosphere is difficult to predict, and therefore, evaluation of the radiation incident on a surface scavenger is an extraordinarily complex procedure.

There is a remarkable development in the evolution of the research literature on the modeling of solar radiation on Earth's surface. Starting from the implementation of the equation [1] for measurements at meteorological stations in the Earth's surface, which allows for the solar irradiation at a given location. From the data of insolation [2] [3] through the statistical treatment of solar irradiation data [4], up to astronomical and meteorological considerations of the phenomenon and the joint application of surface measurements with data satellite [5].
At Spanish level, a formal reference for many years has been in effect (since 1984) the "Solar Radiation Atlas of Spain" [6] conducted by the National Institute of Meteorology of Spain. In September 2005 the "Digital Climatic Atlas of the Iberian Peninsula" was published made at the initiative of the Autonomous University of Barcelona.

Regarding the use of satellite data, it is called to constitute a significant improvement to the procedures used to date and can be used an alternative methodology for the identification and interpretation of solar radiation on Earth's surface, allowing the development of atlas solar radiation more thoroughly and accurately. Its use is justified by the fact that the network of measuring stations is very sparse (mainly for economic reasons), and because traditional extrapolation methods fail to reflect local microclimatic aspects of the study variables [7] [8].

It should be noted that the best results are obtained by the joint application of measured data on surface and satellite images. A work in this direction is the proposed ESRA European Solar Radiation Atlas, which is working with satellite images of the European continent for the period 1985-1988, together with 10 years of records of stations measuring solar radiation surface, to obtain maps of mean monthly global solar radiation with a spatial resolution of $10 \times 10 \mathrm{~km} 2$.

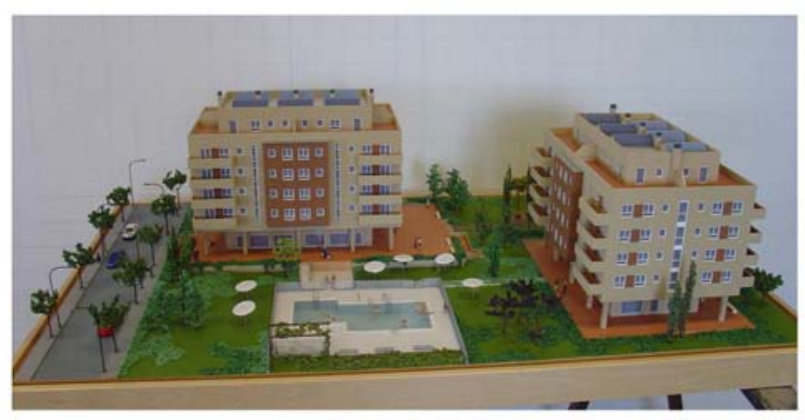

Fig. 01 Model of urbanization taking-up solar PV on the roof.

Regarding the type of sensor and satellite to use, the choice depends on several aspects. On the one hand the spatial resolution, temporal and spectral satellite sensor pairing, and the availability of data for the area and time period considered. In the case of solar radiation, which is very high temporal variation (daily cycle), the election shall be subject to the satellites with the highest temporal resolution. This is the reason why the majority of studies using geostationary or heliosynchronous satellite NOAA. Furthermore, it is interesting to obtain the highest resolution possible and greater observer coverage, in order to reproduce the local aspects of solar irradiation on the largest possible area. 
In the case of Spain, the Meteosat geostationary satellite first generation provides 18 images per day (one every 30 minutes) with a spatial resolution of $5 \mathrm{~km}$ at nadir for the entire European continent and Africa. Meanwhile NOAA satellites provide 3 day image (one every 6 hours) with a spatial resolution of $1.1 \mathrm{~km}$ at nadir with a swath width (width of passage) of the order of $3000 \mathrm{~km}$, enough to cover (depending on the pass) throughout the Iberian Peninsula.

The MSG-1 (Meteosat Second Generation), launched in August 2002 and currently in operation, has been a major breakthrough that greatly improves the spatial resolution (1 $\mathrm{km}$ for the visible channel) and halved the time resolution (15 minutes).

The standard methodology used consists on relating the data obtained from the satellite image sensor according to the employee and the banda in consideration of the irradiation surface; for it, they can be used various procedures, in respect of which there are mainly two types: statistical models and physical models.

Statistical models relating the measured solar irradiance by pyranometers at weather stations with the instantaneous value of the digital level recorded by the satellite image to the pixel which is located the measuring station in question, employing regression analysis and treatment statistics. The relationship thus obtained is assumed valid for estimating solar irradiation on the surface for the entire study area.

Statistical models produce estimates of global solar irradiation on the surface that are about $10 \%$ of the measured values. They may underestimate or overestimate the measured values, depending on model considerations and particularly the weather.

Physical models are based solely on physical considerations, which allow expressing explicitly the exchanges taking place between the radiant energy and the Earth-atmosphere system. To this purpose radiative transfer model can be used. The main variables considered in the calculation are: the scattering and absorption coefficients of the various components of the clean

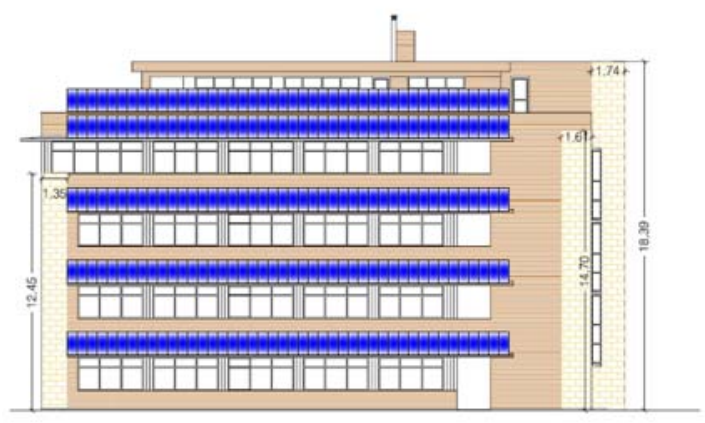

Fig. 02 Infographic of building using solar photovoltaic on the south facade.

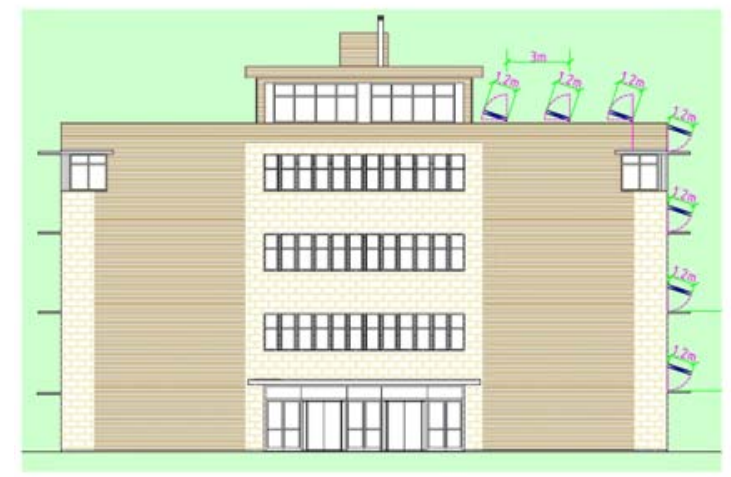

Fig. 03 Detail of an axis solar tracking on the south facade.

atmosphere, albedo and the absorption coefficient of the clouds and albedo surface.

Physical models often make estimates of global surface solar irradiance with errors around $5 \%$ in clear sky conditions and the order of $15 \%$ in overcast conditions [9]. Other authors reported higher values, so we have that for example to get mistakes clear sky between $10 \%$ and $15 \%$, while under overcast the error in the estimate varies between $17 \%$ and $39 \%$ [10].

The calculation of global radiation on an arbitrarily oriented surface is to consider that this radiation can be decomposed into direct radiation (which comes only from solar disk), diffuse radiation (which comes from the sky and is visible on the surface scavenger), and reflected radiation or albedo (which comes from the environment) [11-13].

\section{Optimal orientation procedure of photovoltaic solar systems through the use of a multicellular photovoltaic sensor}

For the capture of solar energy and its conversion into electricity, panels of photovoltaic solar cells are used. The panels are fixed to a support structure which may be fixed or rotatable up to the sun. Photovoltaic solar panels are fitted with tracking devices on two axes to optimize the energy received from the sun by constantly adjusting the spatial orientation of the panel in accordance with changes in altitude and azimuth of the sun throughout the day. This is a complex mechanism, on which have a horizontal and a vertical axis, driven by two motorized gear regulated by a control device that stores the sun's path throughout the day for every day of the year.

In buildings of the northern terrestrial hemisphere, the most contained solar collection plans are the cover and the south facade. The cover [Fig.01], allows the panels having tracking system equipped with two axes. The south facade [Fig.02], only allows monitoring to be provided to an axis [Fig.03]. In both cases a fixed southern orientation and tilt slope variable or fixed according to the optimum angle for the latitude of the 


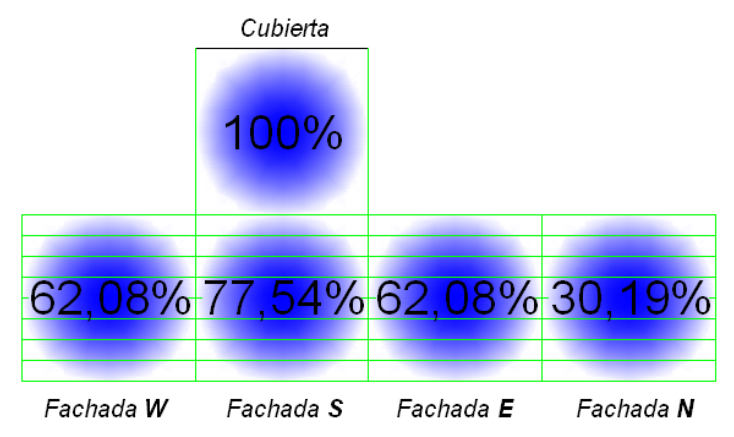

Fig. 04 Percentage of average annual global radiation on the roof and facades.

place can be used. Finally it can dispose of the roof panels integrated in the cover as the slope thereof and the south facade panels according to the their vertical direction.

As it can be seen, we have a large case series, either of fixed or variable components to optimize.

In Fig.04 it is shown the overall irradiation received by each facade of a building either in conjunction with the cover, which has been taken for reference.

If photovoltaic solar panels have, on a fixed structure, with an optimum tilt angle corresponding to the latitude of the place, the optimal generation is:

$$
\begin{aligned}
& \text { Cover: } 14 \%\left(\text { for } \beta=0^{\circ}\right. \text { ) } \\
& \text { Facade: } 47 \%\left(\text { for } \beta=90^{\circ}\right. \text { ) }
\end{aligned}
$$

When using a track structure, the optimal generation will be:

$$
\begin{aligned}
& 2 \mathrm{x} \text { Axis versus static optimal } \beta=47 \% \\
& 1 \mathrm{x} \text { height versus static optimal } \beta=28 \%
\end{aligned}
$$

Analysis of the data above shows that it is very interesting from the standpoint of energy improvement, implementing solar tracking systems.

The state of the art of the slar tracking has been improved by applying a photovoltaic multicellular sensor, as well as an orientation process. The sensor is characterized by comprising several calibrated photovoltaic solar cells, arranged in different planes on a concave or convex support, which are wired to a signal multiplexer adapter, so that by a programmable logic controller (PLC) or a personal computer $(\mathrm{PC})$, it can be measured in real time readings of all calibrated photovoltaic solar cells, with two main applications:

- Measure for characterizing solar.

- Regulation for optimal solar tracking.

For determination of the optimal solar altitude, the sensor is configured in vertical position. The calibrated photovoltaic solar cell of the ones integrating the sensor

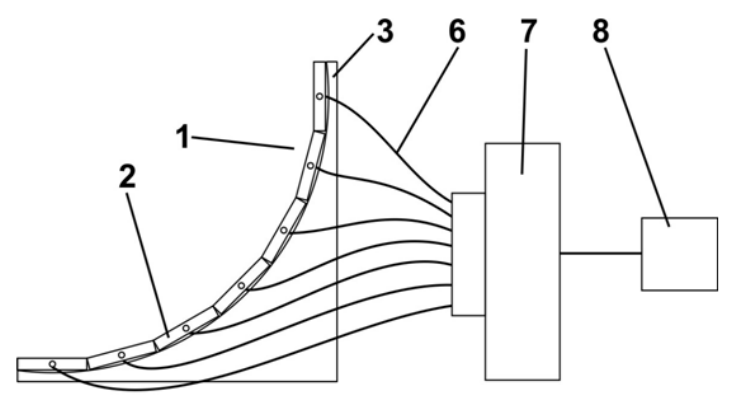

Fig. 05 Sensor with vertical configuration.

that produces the higher output energy level, determines the optimal direction [Fig.05].

For determining the optimal solar azimuth, the sensor is disposed in a horizontal position. The photovoltaic solar cell calibrated for integrating the sensor output that determines the most optimal solar azimuth, being necessary for complete determination of the solar azimuth a dual sensor [Fig.06].

The power output of a solar system depends critically on two environmental variables: incident irradiance and temperature of solar cells. The power is given by the following equation:

$$
P_{S F V}=P^{*} \cdot\left(\frac{G}{G^{*}}\right) \cdot\left[1+K_{T} \cdot\left(T C-T c^{*}\right)\right]
$$

where $\mathrm{P} *$ is the power at Standard Test Conditions (W), $\mathrm{G}$ is the incident irradiance $(\mathrm{W} / \mathrm{m} 2), \mathrm{G} *$, EMC is the irradiance $(1000 \mathrm{~W} / \mathrm{m} 2)$, KT is the coefficient of variation power with temperature (always negative), TC is the cell temperature $\left({ }^{\circ} \mathrm{C}\right)$ and $\mathrm{Tc} *$ is the temperature of the cell EMF $\left(25^{\circ} \mathrm{C}\right)$. The above equation demonstrates the utility of increasing the maximum possible incident irradiance being therefore necessary to implement the solar tracking described above. 


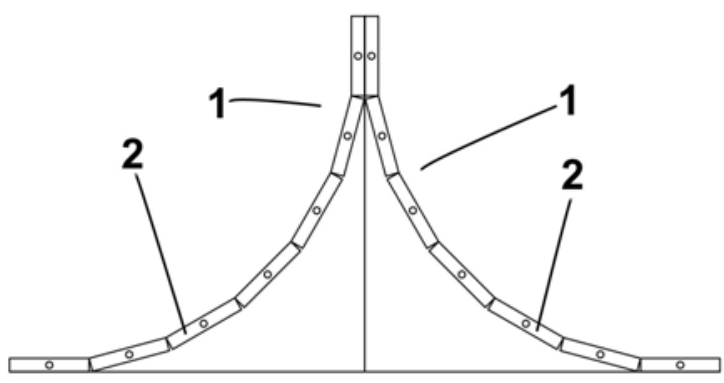

Fig. 06 Sensor with horizontal configuration.

The optimum orientation procedure is valid for monitoring systems as an axis for tracking systems with two axes. The procedure is to implement a function of maximum in a programmable logic controller (PLC) or a personal computer (PC). The PLC or PC will select the calibrated solar cell from all the cells of the photovoltaic multicellular sensor, being selected to the highest reading and the angle of the cell indicating the angle to the solar photovoltaic system as optimal for capture most solar radiation available at the time.

The solar tracking system usually will present as many fixed positions as solar cells have the multicellular calibrated sensor. In this way the solar tracker is significantly simplified, since it is not continuous but with predetermined steps. This system is ideal for applications in small and medium power.

\section{Conclusion}

This article presents a method of orientation of solar photovoltaic systems through the use of a multicellular photovoltaic sensor, allowing real-time control of optimal orientation steerable solar photovoltaic systems, both in one or two axes, and on the other hand to perform a real data acquisition of solar radiation over a period of time, to determine effectively simply and empirically which is the optimal orientation for the systems to be installed.

\section{Acknowledgement}

This paper has been partially supported by a grant of the University of La Rioja.

\section{References}

[1] Angström, A. K., "Solar and terrestrial radiation", Quart. L. R. Met. Soc.,50,pp.121-126, 1924.

[2] Kasten, F., Golchert, H. J., Dogniaux, R. et Lemoine, M., "Atlas européen du rayonnement solaire", Verlag TÜV Rheinhald Gmbh, Colònia. pp. 289 (Vol. I) et 321 (Vol. II), 1984.

[3] Kasten, F., Golchert, H. J., Dogniaux, R. and Lemoine, M., "European solar radiation atlas Springer-Verlag", Berlin. pp. $333,1996$.
[4] Baldasano, J. M., Soriano, C. i Flores, H., "Atlas de radiació solar a Catalunya”, Institut Català d'Energia, Barcelona. pp. $149,2001$.

[5] Flores, H., "Procesamiento digital de imágenes de satélites para la obtención de mapas de radiación solar. Aplicación a Cataluña", Tesis Doctoral,Universidad Politécnica de Calaluña. pp. 200, 2002.

[6] Font, I., "Atlas de radiación solar en España", Instituto Nacional de Meteorología. pp. $44,1984$.

[7] Perez, R., Seals, R., Stewart, R., Zelenka, A. and EstradaCajigal, V., "Using satellite-derived insolation for simulation of solar energy system”, Solar Energy 53,pp.491-495, 1994.

[8] Perez, R., Ineichen, P., Moore, K., Kmiecik, M., Cain, C., George, R., and Vignola F., "A new operational model for satellite-derived irradiances: description and validation", Solar Energy, 73,pp.307-317, 2002.

[9] Gautier, C., Diak, G. and Masse, S., "A simple physical model to estimate incident solar radiation at the surface from GOES satellite data", J. Appl. Meteorol., 19, 8: 1005-1012, 1980.

[10] Laine, V., Venäläinen, A., Heikinheimo, M. and Hyvärinen, O.," Estimation of surface solar global radiation from NOAA AVHRR data in high latitudes “, J. Appl. Meteorol., 38, 12: 1706-1719, 1999.

[11] (C) Sáenz-Díez,J.C., Blanco,J.M., Jiménez,E., et al., Industrial Patent: P201001216, "Sensor fotovoltaico multicelular y procedimiento de orientación" translated as "Multicellular photovoltaic sensor and orientation process"

[12] Sáenz-Díez ,J.C.,Blanco, J.M.,Jiménez,E., et al., Libro: ISBN 978-84-615-0191-5, “Generación microeléctrica mediante energía renovable solar en el espacio urbano, Número de Páginas: 115.

[13] Blanco,J.M. ,Sáenz-Díez ,J.C.,Jiménez,E., et al., Libro: ISBN 978-84-614-9604-4, "Optimización de la producción de energía eléctrica de origen renovable Solar fotovoltaica, Minieólica e Hidroeléctrica", Número de Páginas: 204. 